\title{
$\beta$-Hydroxybutyrate Oxidation in Exercise Is Impaired by Low-Carbohydrate and High-Fat Availability
}

\author{
David J. Dearlove ${ }^{1 * t}$, David Holdsworth ${ }^{1 \dagger}$, Tom Kirk ${ }^{1}$, Leanne Hodson ${ }^{2}$, \\ Evelina Charidemou ${ }^{3}$, Eline Kvalheim ${ }^{4}$, Brianna Stubbs ${ }^{1}$, Andrew Beevers ${ }^{5}$, \\ Julian L. Griffin ${ }^{3}$, Rhys Evans ${ }^{1}$, Jeremy Robertson ${ }^{4}$, Kieran Clarke ${ }^{1}$ and Pete J. Cox ${ }^{1}$ \\ ${ }^{1}$ Department of Physiology, Anatomy and Genetics, University of Oxford, Oxford, United Kingdom, ${ }^{2}$ Oxford Centre for \\ Diabetes, Endocrinology and Metabolism, Oxford NIHR Biomedical Research Centre, University of Oxford, Oxford, \\ United Kingdom, ${ }^{3}$ Department of Biochemistry and Cambridge Systems Biology Centre, University of Cambridge, MRC \\ Human Nutrition Research, Cambridge, United Kingdom, ${ }^{4}$ Department of Chemistry, University of Oxford, Oxford, \\ United Kingdom, ${ }^{5}$ Research and Development Department, Sterling Pharma Solutions Ltd., Cramlington, United Kingdom
}

OPEN ACCESS

Edited by: Hayden White, Griffith University, Australia

Reviewed by:

Tanja Oosthuyse

University of the Witwatersrand, South Africa

Julien Louis,

Liverpool John Moores University, United Kingdom

*Correspondence:

David J. Dearlove

david.dearlove@dpag.ox.ac.uk;

david_dearlove@hotmail.com

†These authors share first authorship

Specialty section

This article was submitted to

Translational Medicine,

a section of the journa

Frontiers in Medicine

Received: 07 June 2021 Accepted: 25 October 2021 Published: 25 November 2021

Citation: Dearlove DJ, Holdsworth D, Kirk T, Hodson L, Charidemou E, Kvalheim E,

Stubbs B, Beevers A, Griffin JL, Evans R, Robertson J, Clarke $K$ and Cox PJ (2021) $\beta$-Hydroxybutyrate Oxidation in Exercise Is Impaired by

Low-Carbohydrate and High-Fat

Availability. Front. Med. 8:721673. doi: 10.3389/fmed.2021.721673
Purpose: In this study, we determined ketone oxidation rates in athletes under metabolic conditions of high and low carbohydrate $(\mathrm{CHO})$ and fat availability.

Methods: Six healthy male athletes completed $1 \mathrm{~h}$ of bicycle ergometer exercise at $75 \%$ maximal power (WMax) on three occasions. Prior to exercise, participants consumed $573 \mathrm{mg} \cdot \mathrm{kg} \mathrm{bw}^{-1}$ of a ketone ester (KE) containing a ${ }^{13} \mathrm{C}$ label. To manipulate $\mathrm{CHO}$ availability, athletes undertook glycogen depleting exercise followed by isocaloric high- $\mathrm{CHO}$ or very-low- $\mathrm{CHO}$ diets. To manipulate fat availability, participants were given a continuous infusion of lipid during two visits. Using stable isotope methodology, $\beta$-hydroxybutyrate $(\beta \mathrm{HB})$ oxidation rates were therefore investigated under the following metabolic conditions: (i) high $\mathrm{CHO}+$ normal fat $(\mathrm{KE}+\mathrm{CHO})$; (ii) high $\mathrm{CHO}+$ high fat $\mathrm{KE}+\mathrm{CHO}+\mathrm{FAT}$ ); and (iii) low $\mathrm{CHO}+$ high fat (KE+FAT).

Results: Pre-exercise intramuscular glycogen (IMGLY) was approximately halved in the $\mathrm{KE}+\mathrm{FAT}$ vs. $\mathrm{KE}+\mathrm{CHO}$ and $\mathrm{KE}+\mathrm{CHO}+\mathrm{FAT}$ conditions (both $p<0.05$ ). Blood free fatty acids (FFA) and intramuscular long-chain acylcarnitines were significantly greater in the $\mathrm{KE}+\mathrm{FAT}$ vs. other conditions and in the $\mathrm{KE}+\mathrm{CHO}+\mathrm{FAT}$ vs. $\mathrm{KE}+\mathrm{CHO}$ conditions before exercise. Following ingestion of the ${ }^{13} \mathrm{C}$ labeled $\mathrm{KE}$, blood $\beta \mathrm{HB}$ levels increased to $\approx 4.5 \mathrm{mM}$ before exercise in all conditions. $\beta \mathrm{HB}$ oxidation was modestly greater in the $\mathrm{KE}+\mathrm{CHO}$ vs. KE+FAT conditions (mean diff. $=0.09 \mathrm{~g} \cdot \mathrm{min}^{-1}, p=0.03 ; d=0.3$ ), tended to be greater in the $\mathrm{KE}+\mathrm{CHO}+\mathrm{FAT}$ vs. KE$+\mathrm{FAT}$ conditions (mean diff. $=0.07 \mathrm{~g} \cdot \mathrm{min}^{-1}$; $p=0.1 ; d=0.3$ ) and were the same in the $\mathrm{KE}+\mathrm{CHO}$ vs. $\mathrm{KE}+\mathrm{CHO}+\mathrm{FAT}$ conditions $(p<0.05 ; d<0.1)$. A moderate positive correlation between pre-exercise IMGLY and $\beta \mathrm{HB}$ oxidation rates during exercise was present $(p=0.04 ; r=0.5)$. Post-exercise intramuscular $\beta \mathrm{HB}$ abundance was markedly elevated in the KE+FAT vs. $\mathrm{KE}+\mathrm{CHO}$ and $\mathrm{KE}+\mathrm{CHO}+\mathrm{FAT}$ conditions (both, $p<0.001 ; d=2.3$ ).

Conclusion: $\beta \mathrm{HB}$ oxidation rates during exercise are modestly impaired by low $\mathrm{CHO}$ availability, independent of circulating $\beta \mathrm{HB}$ levels.

Keywords: ketone, ketosis, exogenous ketosis, oxidation, exercise 


\section{INTRODUCTION}

Ketogenesis is a vital metabolic adaptation to starvation (1). The hepatic synthesis of ketone bodies [mainly $\beta$ hydroxybutyrate $(\beta \mathrm{HB})$ and acetoacetate $(\mathrm{AcAc})$; herein collectively referred to as ketones] predominately from free fatty acid (FFA) links energy stored in adipose tissue to cerebral metabolism (2) under conditions of reduced carbohydrate $(\mathrm{CHO})$ intake. Indeed, ketones replace glucose as the primary metabolic substrate during prolonged starvation (2). Whilst the teleological purpose of ketogenesis is to provide a supplementary fuel for the brain $(1,2)$, most oxidative tissues can metabolize ketones (3). Given its substantial contribution to overall body mass, skeletal muscle is the largest site of ketone uptake and oxidation (3), particularly during exercise (4-6) when metabolic rate is markedly elevated (7). Accordingly, there is interest in whether nutritional ketones, arguably most effectively delivered as a ketone ester (KE) (8), could provide a supplementary fuel to power muscular contraction (9). However, the contribution of exogenous ketone oxidation to whole-body energy expenditure appears to be low in exercising humans, with estimates ranging from 0 to $10 \%(4,6,10,11)$.

Fuel selection within tissues is controlled by dynamic interactions between substrates (12). For example, the glucosefatty acid cycle (Randle cycle) describes the inhibition of glucose oxidation by fatty acids (and ketones) and vice versa $(12,13)$. Indeed, ketones are "out competed" by $\mathrm{CHO}$ - and lipid-derived substrates for oxidation in isolated mitochondria (14). It is plausible, therefore, that ketone oxidation rates might be greater in glycogen depleted muscle, where $\mathrm{CHO}$ competition for oxidation would theoretically be decreased. However, further consideration is that glycogen is a major source of anaplerotic substrate for the Krebs cycle (15), the common pathway in which acetyl-CoA derived from glycolysis, $\beta$-oxidation, and ketolysis is oxidized. Thus, in glycogen-depleted states, such as prolonged vigorous exercise (16) or low $\mathrm{CHO}$ intake (17), ketone oxidation might be impaired.

To determine the effect of circulating and intramuscular substrate concentrations on ketone metabolism, the present study measured $\beta \mathrm{HB}$ oxidation rates in athletes during exercise under conditions of low and high $\mathrm{CHO}$ and fat availability. In doing so, we sought to determine the optimal metabolic conditions under which ketone metabolism might support muscular contraction.

\footnotetext{
Abbreviations: 2PG, 2-Phosphoglyceric acid; 3PG, 3-Phosphoglyceric acid; AcAc, acetoacetate; $\beta \mathrm{HB}, \mathrm{V}$-hydroxybutyrate; BPM, beats per min; CHO, carbohydrate; DHAP, dihydroxyacetone phosphate; DPAG, Department of Physiology, Anatomy and Genetics; EDTA, ethylenediaminetetraacetic acid; F6P, fructose 6-phosphate; FBPN, fructose 1,6-bisphosphate; FFA, free fatty acid; G6P, glucose 6 phosphate; HR, heart rate; IMGLY, intramuscular glycogen; KE, ketone ester; PEP, phosphoenolpyruvic acid; RER, respiratory exchange ratio; RPE, ratings of perceived exertion; RPM, revolutions per min; TTR, tracer to tracee ratio; VCO2, volume of carbon dioxide expelled; VE, ventilatory exchange; VO2, volume of oxygen consumed; VO2, Max maximum oxygen uptake; WMax, maximal power.
}

TABLE 1 | Participant characteristics.

\begin{tabular}{lc}
\hline & Mean \pm SD \\
\hline Age $(\mathrm{yr})$ & $35 \pm 5$ \\
Height $(\mathrm{cm})$ & $184 \pm 13$ \\
Weight $(\mathrm{kg})$ & $82 \pm 17$ \\
$\mathrm{BMl}\left(\mathrm{kg} \mathrm{m}^{2}\right)$ & $23.8 \pm 2.5$ \\
$\mathrm{VO}_{2} \operatorname{Max}\left(\mathrm{L} \mathrm{min}^{-1}\right)$ & $4.8 \pm 0.7$ \\
$\mathrm{VO}_{2} \operatorname{Max}\left(\mathrm{mL} \mathrm{kg} \mathrm{BW}^{-1}\right)$ & $59.0 \pm 7.6$ \\
$\mathrm{~W}_{\operatorname{Max}}$ & $348 \pm 44$ \\
\hline
\end{tabular}

\section{MATERIALS AND METHODS}

\section{Subjects}

Six male endurance athletes (Table 1) were recruited to a random-order controlled, cross-over-design study (Figure 1). One participant withdrew consent for muscle biopsies at two visits (KE+CHO+FAT and $\mathrm{KE}+\mathrm{FAT}$ conditions) and as such, their muscle data was not included in final analyses. Ethical approval for the study was acquired from the Oxfordshire Regional Ethics Committee. All subjects provided written informed consent prior to participation.

Athletes were recruited by direct invitation or having responded to targeted advertisements. Eligibility criteria were men or women aged from 18 to 40 years; undertaking $\geq 10 \mathrm{~h} \cdot \mathrm{wk}^{-1}$ endurance-exercise training for the 3 months prior to enrollment; and being injury and illness free at the time of enrollment. The study exclusion criteria were any previous history of cardiovascular, neuromuscular, endocrine or neurological disease, or any other medical condition requiring long-term medication; smoking of any kind; and pregnancy or current breastfeeding, or female athletes not taking the oral contraceptive pill.

\section{Baseline Testing}

A baseline exercise test was undertaken to determine individual exercise intensities [\% of maximal power $\left(\mathrm{W}_{\mathrm{Max}}\right)$ ] for subsequent study visits. Participants arrived at the Department of Physiology, Anatomy and Genetics (DPAG), the University of Oxford having fasted overnight ( 8 to $10 \mathrm{~h}$ fast). The exercise was performed on an electronically-braked cycling ergometer (Ergoselect 100, Ergoline, Germany). Participants adjusted the handlebar position and saddle height according to personal preference. Individual bike geometry was recorded and kept consistent across all subsequent visits. The ergometer was set to the revolutions per min (RPM)-independent mode, meaning resistance was constant regardless of the cadence held. Water was allowed ad libitum before exercise. The exercise was commenced at $100 \mathrm{~W}$ and increased $25 \mathrm{~W}$ every $3 \mathrm{~min}$ until volitional fatigue. To ensure exercise was undertaken to maximal capacity, two of the following criteria must have been met:

- upon an increase in exercise intensity, the volume of oxygen consumed $\left(\mathrm{VO}_{2}\right)$ was not elevated by more than $0.2 \mathrm{~L} \cdot \mathrm{min}^{-1}$;

- heart rate (HR) was within 10 beats per min (BPM) of an age predicted maximum (220-age); 


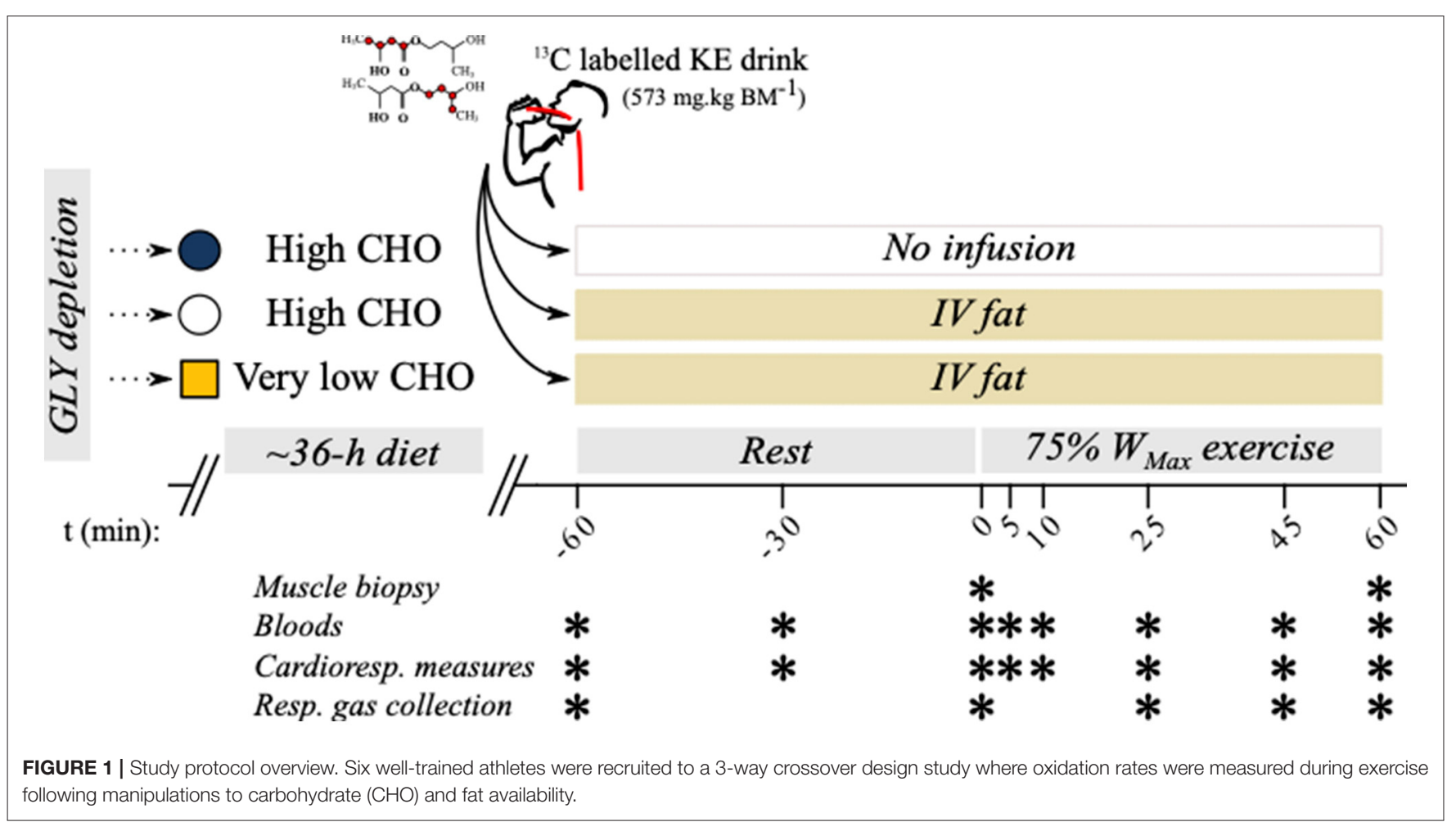

- the respiratory exchange ratio (RER) was $>1.1$; and

- an inability to maintain a cadence $>60$ RPM.

Study investigators provided verbal encouragement during exercise. Respiratory gases were measured continuously through indirect calorimetry. Maximum oxygen uptake $\left(\mathrm{VO}_{2 \mathrm{Max}}\right)$ was defined as the highest $20 \mathrm{~s}$ average for $\mathrm{VO}_{2}$. Maximal power In review $\left(\mathrm{W}_{\mathrm{Max}}\right)$ was calculated according to the formula (18):

$$
W_{\text {Max }}=W_{\text {Step } N-1}+(\text { time elapsed } / 180 \mathrm{sec} \cdot 25 \mathrm{~W})
$$

\section{Study Overview}

$\beta$-hydroxybutyrate oxidation rates were measured during exercise following manipulation of dietary $\mathrm{CHO}$ and circulating FFA levels. The three experimental conditions (Figure 1) studied were as follows:

- $\mathrm{KE}+$ high-CHO diet + normal fat $(\mathrm{KE}+\mathrm{CHO})$;

- $\mathrm{KE}+$ high-CHO diet + high fat $(\mathrm{KE}+\mathrm{CHO}+\mathrm{FAT})$; and

- ketone ester $(\mathrm{KE})+$ low-CHO diet + high fat $(\mathrm{KE}+\mathrm{FAT})$.

Participants undertook these conditions in a random order, which was determined following enrollment.

\section{CHO Availability Manipulations}

Thirty-six hours prior to each study visit, participants undertook a glycogen depleting exercise protocol on the same bicycle ergometer (Ergoselect 100, Ergoline, Germany). This consisted of alternating 2 min "work" and "recovery" intervals commencing at 90 and $50 \% \mathrm{~W}_{\mathrm{Max}}$, respectively. When the participant could no longer hold $90 \% \mathrm{~W}_{\mathrm{Max}}$ for $2 \mathrm{~min}$ (volitional fatigue or inability to hold a cadence $\geq 60 \mathrm{RPM}$ ), the work intensity was reduced by
$10 \%$. This continued until participants could no longer maintain $60 \% \mathrm{~W}_{\text {Max }}$ during work intervals. Participants were instructed to hold a cadence of 80 to 100 RPM, and the bicycle ergometer was set to the RPM-independent mode. This protocol reliably depletes intramuscular glycogen (IMGLY) stores (19).

For the high-CHO availability conditions $(\mathrm{KE}+\mathrm{CHO}$ and $\mathrm{KE}+\mathrm{CHO}+\mathrm{FAT}$ ), participants then adopted a high-CHO diet (target of $7 \mathrm{~g} \cdot \mathrm{kg} \mathrm{bw}^{-1}$ ) lasting until the evening before the study visits (refer to Supplementary Information 1 for an example diet diary). Athletes were familiar with the practice of pre-race $\mathrm{CHO}$ loading. This level of $\mathrm{CHO}$ intake is in-line with current recommendations to support IMGLY restoration during exercise training (6 to $12 \mathrm{~g} \cdot \mathrm{kg} \mathrm{bw}^{-1}$ ) (20). For the low-CHO availability visit (condition: $\mathrm{KE}+\mathrm{FAT}$ ), participants adopted a strict verylow-CHO diet (target of $\leq 5 \%$ total energy derived from $\mathrm{CHO}$ ), with the goal of ensuring that intramuscular glycogen (IMGLY) was not fully replenished (21). For all conditions, participants were supplied with food and drink items and kept a diet diary.

\section{Study Visits}

Participants attended DPAG having fasted overnight (8 to $10 \mathrm{~h}$ fast). A 22-gauge catheter (BD Venflon ${ }^{\mathrm{TM}}$ Pro Safety; BD, UK) was inserted into an antecubital vein of the arm. A three-way tap (BD Connecta ${ }^{\mathrm{TM}}$ Plus Stopcock; BD) was attached, and a baseline blood sample was collected into an ethylenediaminetetraacetic acid (EDTA) tube $(t=-60 \mathrm{~min})$. Blood samples were stored in an ice water bath until the completion of the visit. Resting respiratory gases and $\mathrm{HR}$ were measured. Respiratory gas samples were collected using a Douglas bag. A second 22gauge catheter was inserted into an antecubital vein on the 
contralateral arm for the continuous infusion of $20 \%$ Intralipid ${ }^{\circledR}$ (20\% soybean oil, $1.2 \%$ egg yolk phospholipids, and $2.25 \%$ glycerin and water; Baxter Healthcare, US) at $50 \mathrm{~mL} \cdot \mathrm{h}^{-1}$ for the duration of the visit. Participants then consumed a drink containing $573 \mathrm{mg} \cdot \mathrm{kg} \mathrm{bw}^{-1}$ of $\beta \mathrm{HB}$ monoester (d- $\beta \mathrm{HB}-R-1,3-$ butanediol monoester; $\mathrm{T} \Delta \mathrm{S}$, UK) diluted in water. A weight adjusted volume of a bespoke ${ }^{13} \mathrm{C} \mathrm{KE}$ tracer was added to the drinks, providing a relative enrichment of $\approx 50 \%$. The methods used to synthesize the ${ }^{13} \mathrm{C}$ tracer have been described previously (6). Participants were then prepared for a biopsy of the vastus lateralis muscle using an aseptic technique previously described (22). Samples were attained from separate incisions spaced $\approx 5 \mathrm{~cm}$ apart before and immediately after exercise. Tissue was frozen immediately in liquid nitrogen and subsequently stored at $-80^{\circ} \mathrm{C}$. Further resting (post-drink) blood samples and cardiorespiratory measures were taken at $t=-30$ and $0 \mathrm{~min}$. A resting respiratory gas sample was collected at $t=0 \mathrm{~min}$. Participants then undertook $60 \mathrm{~min}$ of cycling exercise at $75 \%$ $\mathrm{W}_{\text {Max }}$. Blood samples, cardiorespiratory measures, and ratings of perceived exertion (RPE) were taken at $t=5,10,25,45$, and 60 min during exercise. Respiratory gas samples were collected via a Douglas bag during exercise at $t=25,45$, and $60 \mathrm{~min}$.

\section{Blood Sampling and Analysis}

$\beta$-hydroxybutyrate concentration was analyzed immediately from venous blood samples (Freestyle Optium Neo, Abbott Laboratories, USA). Blood samples were centrifuged (10 min at $3,600 \mathrm{RPM}, 4^{\circ} \mathrm{C}$ ). The serum component was transferred to Eppendorf tubes, which were stored at $-25^{\circ} \mathrm{C}$ until later analysis. Samples were analyzed for glucose, lactate, and FFA using a semi-automated bench top analyser (Pentra C400, Horiba Medical, France).

\section{Cardiorespiratory Measurements}

Participants wore a snug fitting face mask (Hans Rudolph, USA) attached to a calibrated indirect calorimeter (Metalyzer 3BR2, Cortex Biophysik, Germany) for the measurement of respiratory gas compositions and ventilatory flow. Values were displayed in real time using Metasoft ${ }^{\circledR}$ (v7.9.1, Cortex Biophysik, Germany). Subjects wore a Polar HR monitor (T31, Polar Electro, Finland) that communicated with the Metalyzer via a receiver cable attached to the ergometer. Cardiorespiratory data was exported in Excel $^{\circledR}$ (Microsoft Corporation, USA) for further analysis. Clearly, aberrant values were omitted, and a minimum $30 \mathrm{~s}$ average was taken for each measurement point.

\section{Respiratory Gas Sampling}

Immediately following pulmonary gas measurements at $t=-60$, $0,25,45$, and $60 \mathrm{~min}$, participants breathed into a mouthpiece containing a one-way valve that was connected to a $50 \mathrm{~L}$ Douglas bag. Duplicate respiratory gas samples were aspirated via a sealed port into $12 \mathrm{ml}$ Exetainer $^{\mathrm{TM}}$ vials (Labco, UK). Vials were subsequently stored at room temperature.

\section{Gas Chromatography-Mass Spectrometry}

The ${ }^{13} \mathrm{C}$ enrichment in drinks was determined by gas chromatography-mass spectrometry after derivatisation with a trimethylsilyl group (23). The tracer to tracee ratio (TTR) $\left({ }^{13} \mathrm{CO}_{2}\right.$ $/{ }^{12} \mathrm{CO}_{2}$ ) in respired gases was determined using previously published methods (24).

\section{Calculation of $\beta \mathrm{HB}$ Oxidation}

$\beta$-hydroxybutyrate oxidation rate $\left(\mathrm{g} \cdot \mathrm{min}^{-1}\right)$ was estimated from the TTR using the following equation.

$$
\begin{aligned}
& V_{C O}\left(\left(\mathrm{TTRCO}_{2 \text { expired }}-\mathrm{TTRCO}_{2 \text { pre-drink }}\right) /\right. \\
& \left.\left(\mathrm{TTR}_{\text {labelled drink }}-\mathrm{TTR}_{\text {unlabelled drink }}\right)\right)(1 / \kappa)
\end{aligned}
$$

The molar mass of $\beta \mathrm{HB}$ was assumed to be $104.1 \mathrm{~g} \cdot \mathrm{mol}^{-1}$ and $\kappa$ $=$ the volume of ${ }^{13} \mathrm{CO}_{2}$ produced from the complete oxidation of $1 \mathrm{~g}$ of $\beta \mathrm{HB}(0.86 \mathrm{~L})$.

\section{Determination of IMGLY}

Glycogen extraction from muscle samples was performed according to previously published methods (25). Briefly, muscle samples $(\approx 15 \mathrm{mg})$ were freeze dried within fenestrated Eppendorf tubes for $72 \mathrm{~h}$. Dry weights were recorded for each sample, and samples were transferred to homogenization vials (product code: CK28, Bertin Instruments, UK) containing 500 $\mu \mathrm{l}$ of $1 \mathrm{M} \mathrm{HCl}$. Samples were homogenized in a Precellys tissue homogenizer (Bertin Instruments, UK) and placed in an $80^{\circ} \mathrm{C}$ water bath for $2 \mathrm{~h}$ with occasional vortexing. Once cooled to room temperature, samples were neutralized through the addition of $250 \mu \mathrm{l}$ Tris/KOH saturated with KCl. Samples were then centrifuged for $15 \mathrm{~min}\left(4^{\circ} \mathrm{C}, 14,000 \mathrm{~g}\right)$, and the supernatant was removed. Finally, samples were assayed for glucose using the hexokinase method on a semi-automated benchtop analyser (Pentra C400, Horiba Medical, France). Glycogen measurements were determined in a single muscle biopsy sample for each participant.

\section{Muscle Metabolite Analysis}

Glycolytic and Krebs cycle metabolites, carnitine species, and $\beta$-hydroxybutyric acid were measured in pre- and postexercise muscle biopsy samples by liquid chromatographymass spectrometry. Refer to Supplementary Information 2 for a detailed description of the methods employed.

\section{Statistics}

Change in blood $\beta \mathrm{HB}$ concentration was used as a surrogate measure of $\beta \mathrm{HB}$ oxidation for the purpose of a priori power calculations. We have previously established that consuming 573 $\mathrm{mg} \cdot \mathrm{kg} \mathrm{bw}^{-1} \mathrm{KE}$ before exercise causes blood $\beta \mathrm{HB}$ levels to reach (mean $\pm \mathrm{SD}$ ) $3.42 \mathrm{mM} \pm 0.21 \mathrm{mM}$ after $60 \mathrm{~min}$ of exercise at $75 \%$ WMax (22). We powered our study to detect a $10 \%$ increase in blood $\beta \mathrm{HB}$ in the glycogen-depleted vs. glycogen-repleted state. This equated to an effect size $f=\approx 0.7$. Using G*Power (26), with an alpha probability of 0.05 and power of 0.8 , we required $n=6$ participants within a 3 group, repeated measures, within factors design study. The present work was conducted before our laboratory's published investigation into the effects of blood $\beta \mathrm{HB}$ concentration and exercise intensity on $\beta \mathrm{HB}$ oxidation rates (6) and as such, we did not have this data available for power calculations. 
Significance was determined as $p<0.05$. Unless otherwise stated, data are presented as mean differences with 95\% CI and Cohen's d effect sizes within the text and mean $\pm \mathrm{SD}$ within figures. All data were analyzed in Prism version 9.0.2 (GraphPad Software, USA). Where data did not meet parametric test assumptions, log transformations were applied (all analyses were performed on the transformed data, but non-transformed data are presented in Figures and Results) or appropriate non-parametric tests were used. A one-way repeated measures ANOVA was performed where a single independent variable containing multiple levels was present. A two-way repeated measures ANOVA was used when multiple independent variables were present. Mixed effects models were used to analyse repeated measures data with missing data points. Significant ANOVA effects are reported within the text and/or figures. Appropriate post-hoc comparisons were used to investigate main and simple effects. Correlations were investigated through Pearson correlation coefficients.

\section{RESULTS}

\section{Substrate Manipulations}

Time to exhaustion during glycogen depleting exercise, performed $36 \mathrm{~h}$ before study visits, was comparable between conditions $(\mathrm{KE}+\mathrm{CHO}=($ mean $\pm \mathrm{SD}) 116 \pm 17 \mathrm{~min}$, $\mathrm{KE}+\mathrm{CHO}+\mathrm{FAT}=105 \pm 15 \mathrm{~min}$, and $\mathrm{KE}+\mathrm{FAT}=117 \mathrm{~min}$ $\pm 15 \mathrm{~min})$. Participant-reported pre-visit $(\approx 36 \mathrm{~h})$ dietary macronutrient compositions were comparable between the high $\mathrm{CHO}$ availability conditions $(\mathrm{KE}+\mathrm{CHO}$ and $\mathrm{KE}+\mathrm{CHO}+\mathrm{FAT}$ ), with $\mathrm{CHO}$ representing $\approx 65 \%$ of total energy intake (Supplementary Information 3). Conversely, the contribution of $\mathrm{CHO}$ to overall energy intake was just $\approx 3 \%$ in the KE+FAT condition. Total energy intake was comparable between all conditions.

Dietary manipulations caused deviations in pre-exercise IMGLY content (Figure 2A; ANOVA, $p=0.006$ ). Pre-exercise IMGLY was approximately halved in the $\mathrm{KE}+\mathrm{FAT}$ vs. $\mathrm{KE}+\mathrm{CHO}$ (mean diff. $=78.6 \mathrm{mmol}$ glycosyl units $\cdot \mathrm{kg}$ dry $\mathrm{wt}^{-1} ; 95 \% \mathrm{CI}=$ $19.8 \mathrm{mmol}$ glycosyl units. $\mathrm{kg}$ dry $\mathrm{wt}^{-1}$ to $137.4 \mathrm{mmol}$ glycosyl units. $\mathrm{kg}$ dry $\mathrm{wt}^{-1} ; d=2.2 ; p=0.04$ ) and $\mathrm{KE}+\mathrm{CHO}+\mathrm{FAT}$ (mean diff. $=82.4 \mathrm{mmol}$ glycosyl units $\cdot \mathrm{kg}$ dry $\mathrm{wt}^{-1} ; 95 \% \mathrm{CI}=23.6$ mmol glycosyl units. $\mathrm{kg}$ dry $\mathrm{wt}^{-1}$ to $141.2 \mathrm{mmol}$ glycosyl units $\cdot \mathrm{kg}$ dry $\left.\mathrm{wt}^{-1} ; d=1.7 ; p=0.01\right)$.

The very-low-CHO diet also raised circulating FFA (Figure 2B; ANOVA: Time ${ }^{\star}$ Condition Interaction, $p<0.001$ ), with plasma FFA concentration being greater at $t=-60 \mathrm{~min}$ (fasted) in the $\mathrm{KE}+\mathrm{FAT}$ vs. $\mathrm{KE}+\mathrm{CHO}$ (mean diff. $=0.42$ $\mathrm{mM} ; 95 \% \mathrm{CI}=0.26$ to $0.57 \mathrm{mM} ; d=2.0 ; p<0.001)$ and $\mathrm{KE}+\mathrm{CHO}+\mathrm{FAT}$ (mean diff. $=0.30 \mathrm{mM} ; 95 \% \mathrm{CI}=0.15$ to 0.45 $\mathrm{mM} ; d=0.8 ; p<0.001)$ conditions. Following commencement of the intravenous lipid infusion in the $\mathrm{KE}+\mathrm{CHO}+\mathrm{FAT}$ and KE+FAT conditions, plasma FFA levels were significantly different between all conditions at rest and throughout exercise. The intravenous lipid infusion also raised circulating triglyceride levels (ANOVA: Time*Condition Interaction, $p$ 0.01), which were the same in all conditions pre-infusion $(t=60 \mathrm{~min})$, but significantly greater in the $\mathrm{KE}+\mathrm{CHO}+\mathrm{FAT}$ vs. $\mathrm{KE}+\mathrm{CHO}$ condition at all measurements post-infusion, and significantly greater in the $\mathrm{KE}+\mathrm{FAT}$ vs. $\mathrm{KE}+\mathrm{CHO}$ condition at $t=25$ and 60 min during exercise (Figure 2C).

Consumption of $573 \mathrm{mg} \cdot \mathrm{kg} \mathrm{bw}^{-1} \mathrm{KE}$ caused blood $\beta \mathrm{HB}$ to rise similarly in all conditions, peaking at $\approx 4.5 \mathrm{mM}$ preexercise (Figure 2D). Blood $\beta \mathrm{HB}$ concentration was comparable between conditions throughout the exercise. Taken together, study interventions created three distinct metabolic conditions in which to investigate $\beta \mathrm{HB}$ oxidation.

\section{$\beta$ HB Oxidation}

A significant Condition effect was present for $\beta \mathrm{HB}$ oxidation rates $(p=0.03$; Figure $3 \mathrm{~A})$, which were greater in the $\mathrm{KE}+\mathrm{CHO}$ vs. KE+FAT conditions (mean diff. $=0.09 \mathrm{~g} \cdot \mathrm{min}^{-1} ; 95 \% \mathrm{CI}$ $=0.01$ to $0.17 \mathrm{~g} \cdot \mathrm{min}^{-1} ; d=0.3 ; p=0.03$ ) and tended to be greater in the $\mathrm{KE}+\mathrm{CHO}+\mathrm{FAT}$ vs. $\mathrm{KE}+\mathrm{FAT}$ conditions (mean diff. $=0.07 \mathrm{~g} \cdot \mathrm{min}^{-1} ; 95 \% \mathrm{CI}=-0.01$ to $0.15 \mathrm{~g} \cdot \mathrm{min}^{-1} ; d=$ $0.3 ; p=0.1)$. However, exploratory post-hoc analyses suggested that $\beta \mathrm{HB}$ oxidation rates were greater in the $\mathrm{KE}+\mathrm{CHO}+\mathrm{FAT}$ vs. $\mathrm{KE}+\mathrm{FAT}$ condition at all time points during exercise, with similar effect sizes to the $\mathrm{KE}+\mathrm{CHO}$ vs. $\mathrm{KE}+\mathrm{FAT}$ comparisons (refer to Supplementary Information 4). There was no difference in $\beta \mathrm{HB}$ oxidation rates between high- $\mathrm{CHO}$ availability conditions with or without the lipid infusion (mean diff. $=0.02 \mathrm{~g} \cdot \mathrm{min}^{-1}$; $95 \% \mathrm{CI}=-0.06$ to $\left.0.11 \mathrm{~g} \cdot \mathrm{min}^{-1} ; d<0.1 ; p=0.7\right)$. A main effect of time was also present $(p<0.001)$, with $\beta \mathrm{HB}$ oxidation rates being markedly increased during exercise vs. rest in all conditions (all $p<0.001$ ). During exercise, $\beta \mathrm{HB}$ oxidation rates remained stable in all conditions. There was a moderate positive correlation between pre-exercise IMGLY and mean $\beta \mathrm{HB}$ oxidation rates during exercise $(r=0.5 ; p=0.04$; Figure 3B). A main effect of Time was present for the contribution of $\beta \mathrm{HB}$ to overall energy expenditure $(p=0.04$; Figure $3 \mathrm{C})$. In the $\mathrm{KE}+\mathrm{CHO}$ and $\mathrm{KE}+\mathrm{CHO}+\mathrm{FAT}$ conditions, the contribution of $\beta \mathrm{HB}$ to overall energy expenditure fell from rest to all exercise measurements (all $p<0.001$ ). However, this effect was not present in the $\mathrm{KE}+\mathrm{FAT}$ condition.

\section{Cardiorespiratory and Exertion Measurements}

Exercise stimulated an increase in $\mathrm{VO}_{2}$, ventilatory exchange (VE), and heart rate (HR); however, no differences between conditions were observed at any time point (Figures $4 A, C, D$ ). A Condition effect was present for the volume of carbon dioxide expelled $\left(\mathrm{VCO}_{2}\right)(p=0.003$; Figure $4 \mathrm{~B})$, which was greater in the $\mathrm{KE}+\mathrm{CHO}$ vs. $\mathrm{KE}+\mathrm{FAT}$ conditions (mean diff. $=0.05 \mathrm{~L} \cdot \mathrm{min}^{-1}$; $95 \% \mathrm{CI}=0.02$ to $\left.0.07 \mathrm{~L} \cdot \mathrm{min}^{-1} ; d=0.1 ; p=0.002\right)$. There was also a Condition effect for RER ( $p=0.002$; Figure 4E), which was lower (indicating greater fat oxidation) in the KE+FAT conditions (mean diff. $=0.06 ; 95 \% \mathrm{CI}=0.02$ to $0.09 ; d=0.6$; $p=0.002$ ) and $\mathrm{KE}+\mathrm{CHO}+\mathrm{FAT}$ conditions (mean diff. $=0.05$; $95 \% \mathrm{CI}=0.02$ to $0.08 ; d=0.5 ; p=0.006$ ). Perceived exertion during exercise was greater following the adoption of the verylow-CHO diet (Figure 4F; ANOVA: Condition, $p=0.009$ ), being elevated in the $\mathrm{KE}+\mathrm{FAT}$ vs. $\mathrm{KE}+\mathrm{CHO}$ (mean diff. $=2.2 ; 95 \% \mathrm{CI}$ $=0.7$ to $3.6 ; d=1.3 ; p=0.005)$ and $\mathrm{KE}+\mathrm{CHO}+\mathrm{FAT}$ conditions (mean diff. $=2.1 ; 95 \% \mathrm{CI}=0.7$ to $3.6 ; d=1.5 ; p=0.005$ ). 

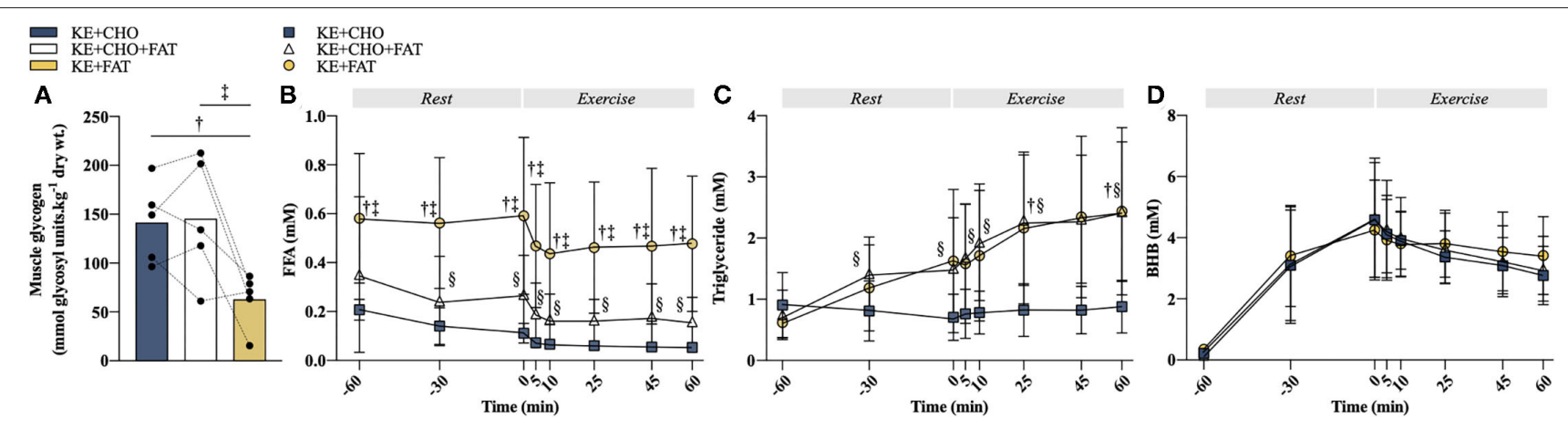

FIGURE 2 | Substrate manipulations. (A) Pre-exercise intramuscular glycogen (IMGLY). (B) Plasma free fatty acid (FFA) concentration at rest and during exercise. (C) Plasma triglyceride concentration at rest and during exercise. (D) Blood $\beta \mathrm{HB}$ concentration at rest and during exercise. Significant post-hoc comparisons: $\dagger=$ ketone ester (KE)+CHO vs. KE+FAT; $\ddagger=\mathrm{KE}+\mathrm{CHO}+\mathrm{FAT}$ vs. $\mathrm{KE}+\mathrm{FAT} ; \S=\mathrm{KE}+\mathrm{CHO}$ vs. $\mathrm{KE}+\mathrm{CHO}+\mathrm{FAT}$. Values $=$ mean $\pm \mathrm{SD}$.

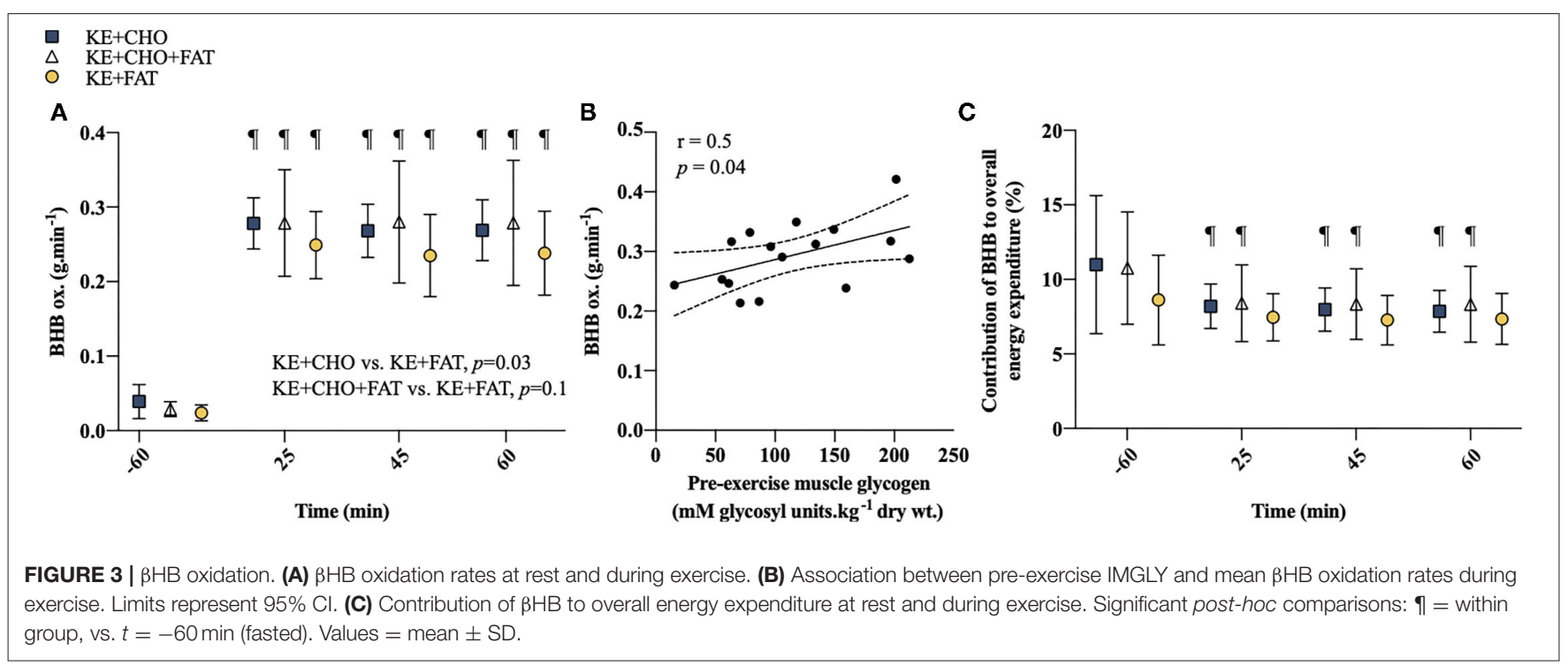

\section{Blood Metabolites}

At $t=5 \mathrm{~min}$, blood glucose was lower in the $\mathrm{KE}+\mathrm{CHO}+\mathrm{FAT}$ vs. $\mathrm{KE}+\mathrm{CHO}$ (mean diff. $=0.64 ; 95 \% \mathrm{CI}=0.02$ to $1.25 ; d=$ $0.8 ; p=0.04$ ) and $\mathrm{KE}+\mathrm{FAT}$ (mean diff. $=1.04 ; 95 \% \mathrm{CI}=0.43$ to $1.66 ; d=1.0 ; p<0.001)$ conditions. Blood glucose was also lower in the $\mathrm{KE}+\mathrm{FAT}$ vs. $\mathrm{KE}+\mathrm{CHO}$ conditions at $t=60 \mathrm{~min}$ (mean diff. $=0.74 ; 95 \% \mathrm{CI}=0.13$ to $1.37 ; d=0.3 ; p=0.01$; ANOVA, Time $*$ Condition Interaction, $p=0.04$; Figure $5 \mathrm{~A})$. No between group differences were observed for blood lactate (Figure 5B).

\section{Intramuscular $\beta \mathrm{HB}$}

Intramuscular $\beta \mathrm{HB}$ abundance was comparable in all conditions in pre-exercise muscle samples (Figure 6A). Exercise stimulated an increase in intramuscular $\beta \mathrm{HB}$ in the $\mathrm{KE}+\mathrm{FAT}$ condition only (mean diff. $=0.003 \mathrm{AU} ; 95 \% \mathrm{CI}=0.001$ to $0.004 \mathrm{AU} ; d=$ 2.3; $p<0.001$; ANOVA, Condition ${ }^{*}$ Time Interaction, $p=0.03$ ). Post-exercise muscle $\beta \mathrm{HB}$ was markedly elevated in the KE+FAT vs. $\mathrm{KE}+\mathrm{CHO}$ and $\mathrm{KE}+\mathrm{CHO}+\mathrm{FAT}$ conditions (mean diff. $=$ 0.002 ; $95 \% \mathrm{CI}=0.001$ to $0.004 \mathrm{AU} ; d=2.3 ; p<0.001$ ). There was a moderate negative relationship between intramuscular $\beta \mathrm{HB}$ abundance and $\beta \mathrm{HB}$ oxidation rates $(r=-0.6, p=0.02$; Figure 6B).

\section{Intramuscular Acylcarnitines, Glycolytic Intermediates, and Krebs Cycle Intermediates}

We sought to investigate whether changes in targeted intramuscular metabolic pathways might explain observed differences in $\beta \mathrm{HB}$ oxidation rates. Baseline and postexercise long-chain acylcarnitine (C12 to $\mathrm{C} 18)$ abundance was significantly greater in the $\mathrm{KE}+\mathrm{CHO}+\mathrm{FAT}$ and $\mathrm{KE}+\mathrm{FAT}$ vs. $\mathrm{KE}+\mathrm{CHO}$ conditions (ANOVA: Condition, $p<0.001$; Time ${ }^{\star}$ Condition Interaction, $p<0.001$; Figure 6C and Supplementary Information 5 for individual carnitine species comparisons). Notably, their abundance was also greater in the $\mathrm{KE}+\mathrm{CHO}+\mathrm{FAT}$ vs. $\mathrm{KE}+\mathrm{FAT}$ condition at baseline. Exercise caused a significant decrease in long-chain acylcarnitines in the $\mathrm{KE}+\mathrm{CHO}+\mathrm{FAT}$ and $\mathrm{KE}+\mathrm{FAT}$ conditions only. 

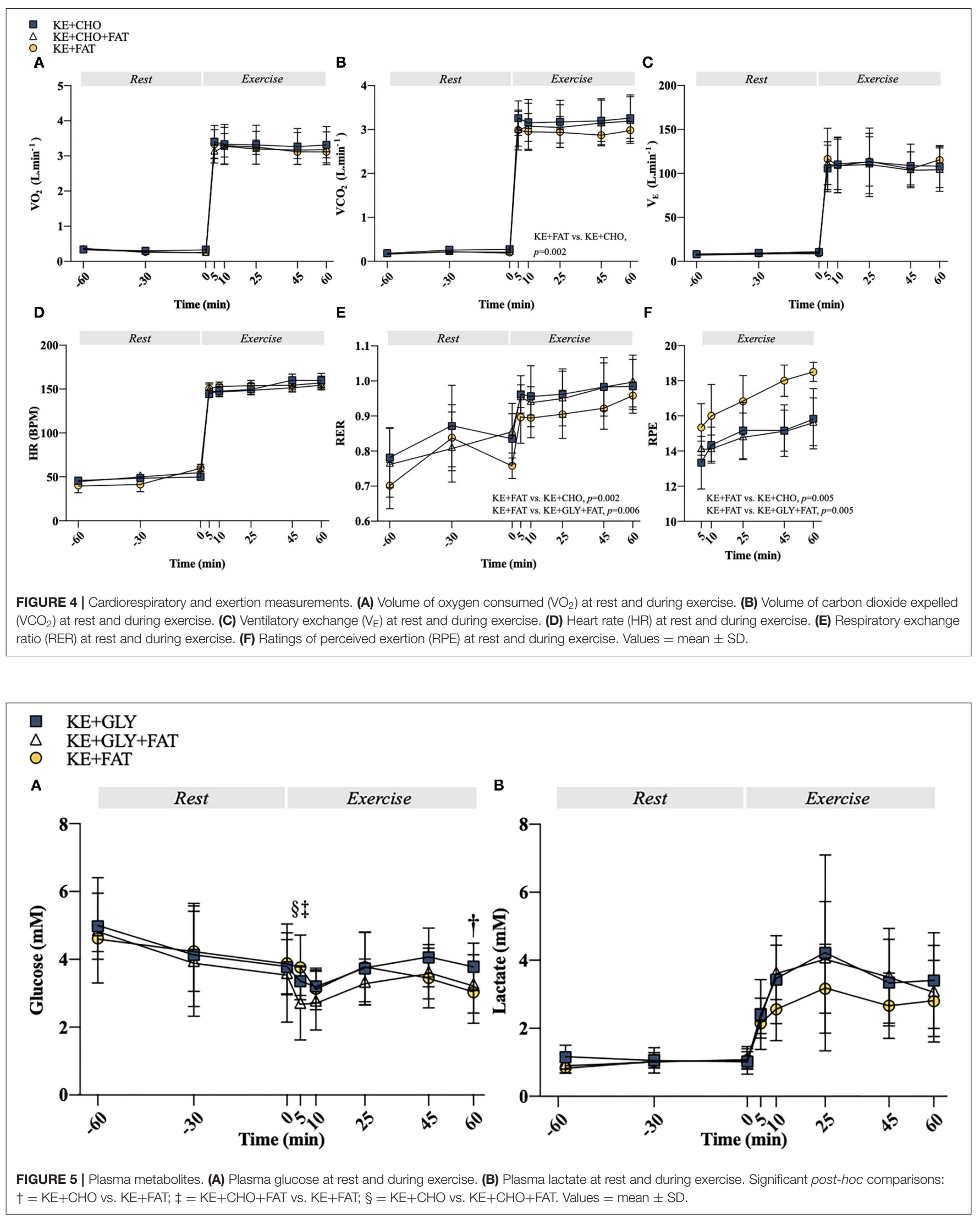


\section{$\mathrm{KE}+\mathrm{CHO}$ \\ KE+CHO+FAT \\ KE+FAT}

A

(
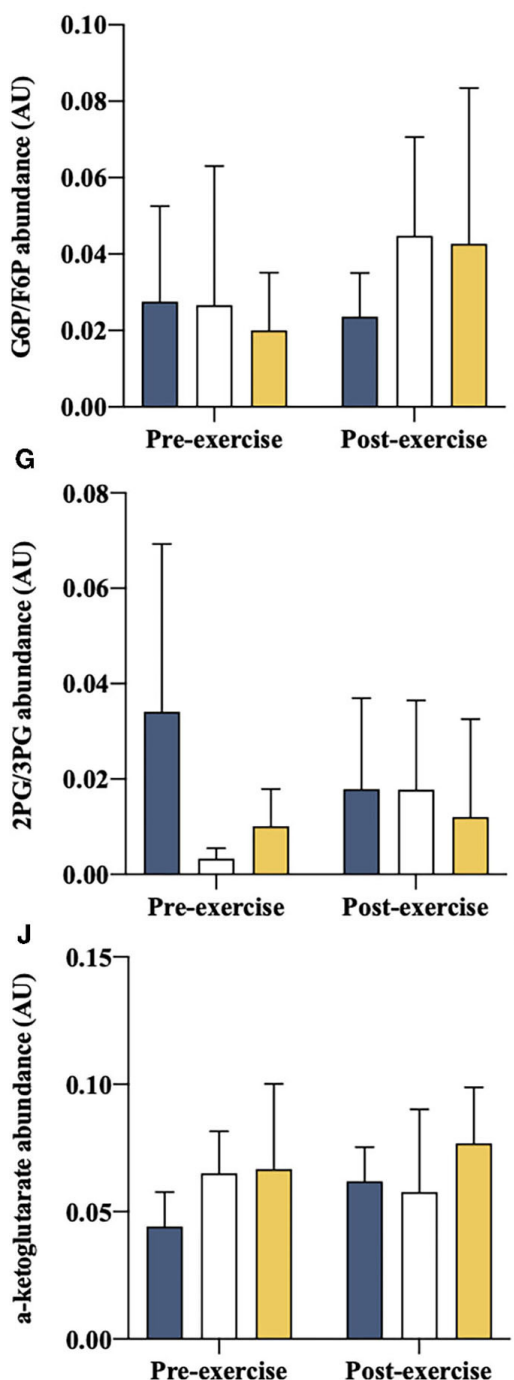

B
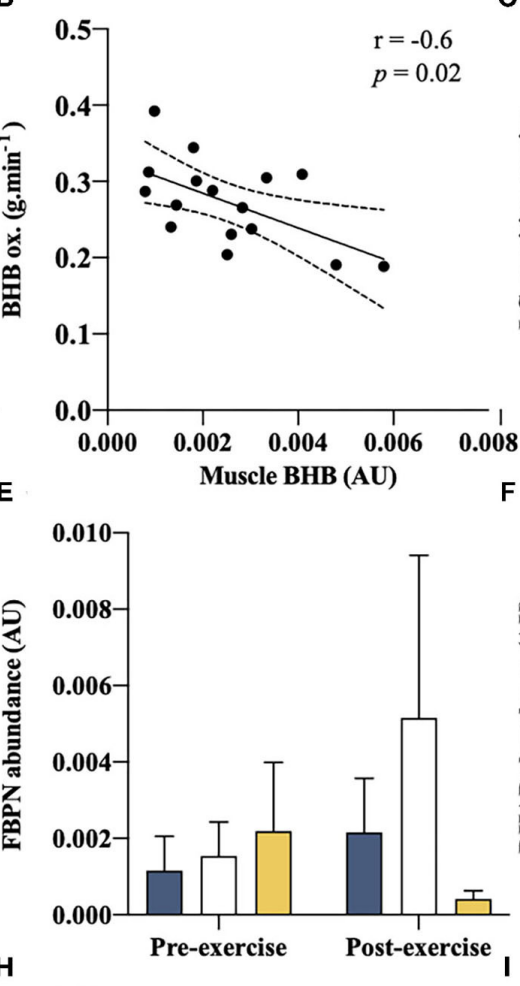

$\mathbf{0 . 0 8}$

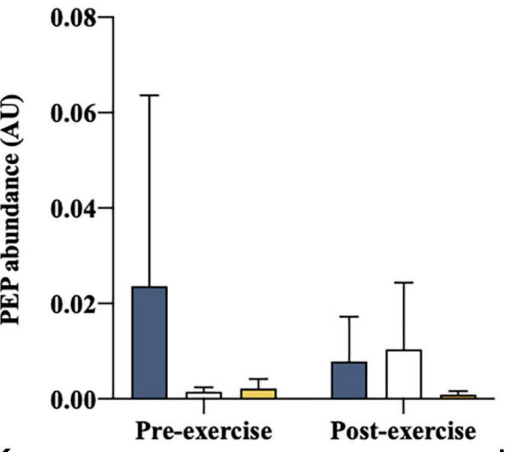

K

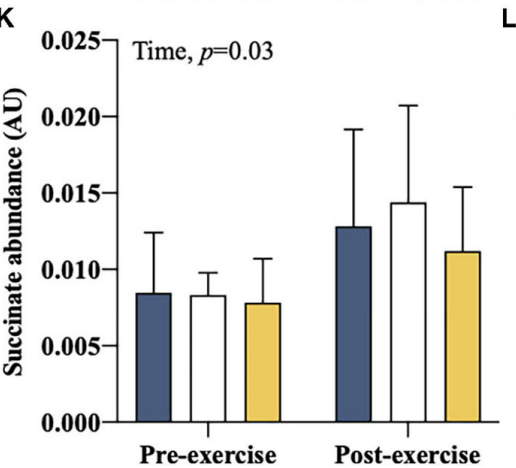

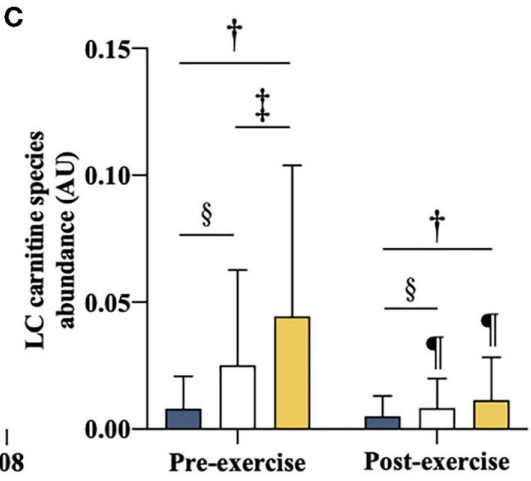

$\mathbf{F}$
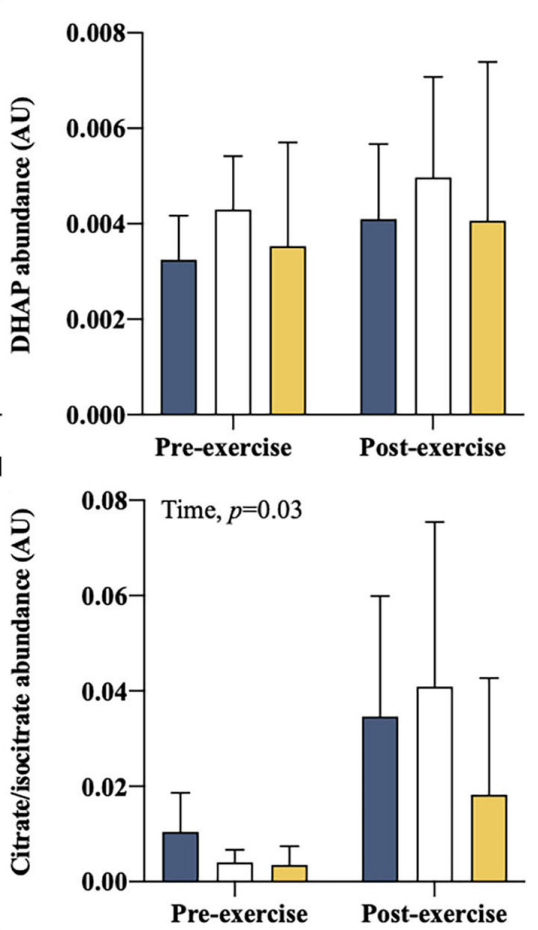

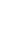

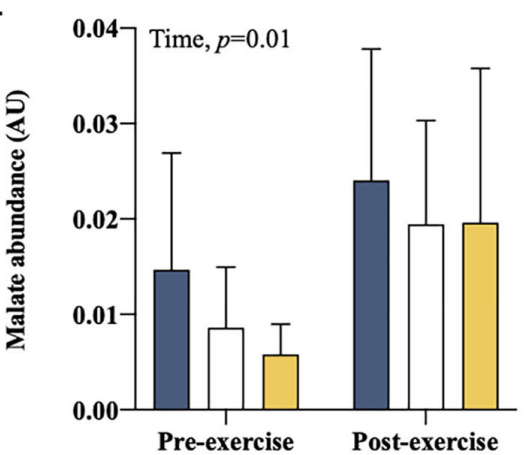

FIGURE 6 | Intramuscular metabolites. (A) $\beta \mathrm{HB}$ pre- and post-exercise. (B) Association between post-exercise intramuscular $\beta \mathrm{HB}$ and $\beta \mathrm{HB}$ oxidation rate at $t=$ 60 min. Limits represent $95 \%$ Cl. (C) Long-chain acylcarnitines (C12 to C18) abundance pre- and post-exercise. (D) glucose 6 phosphate (G6P)/fructose 6-phosphate (F6P) pre- and post-exercise. (E) fructose 1,6-bisphosphate (FBPN) pre- and post-exercise. (F) dihydroxyacetone phosphate (DHAP) pre- and post-exercise. (G) 2-Phosphoglyceric acid (2PG)/3-Phosphoglyceric acid (3PG) pre- and post-exercise. (H) phosphoenolpyruvic acid (PEP) pre- and post-exercise. (I) Citrate/isocitrate pre- and post-exercise. (J) $\alpha$-ketoglutarate pre- and post-exercise. (K) Succinate pre- and post-exercise. (L) Malate pre- and post-exercise. Significant post-hoc comparisons: $\dagger=\mathrm{KE}+\mathrm{CHO}$ vs. $\mathrm{KE}+\mathrm{FAT} ; \ddagger=\mathrm{KE}+\mathrm{CHO}+\mathrm{FAT}$ vs. $\mathrm{KE}+\mathrm{FAT} ; \S=\mathrm{KE}+\mathrm{CHO}$ vs. $\mathrm{KE}+\mathrm{CHO}+\mathrm{FAT}$; $=$ Pre- vs. post-exercise. Values $=$ mean $\pm \mathrm{SD}$. 
Intramuscular glycolytic intermediates were the same in all conditions (Figures 6D-H). A main ANOVA effect of time was present for citrate, succinate, and malate (all $p<0.05$; Figures 6I-L), although no within group pre- vs. post-exercise differences were present. No between group differences were observed for measured Krebs cycle intermediates.

\section{DISCUSSION}

The effect of $\mathrm{CHO}$ and fat availability on human ketone oxidation was unknown. In the present study, we demonstrated that $\beta \mathrm{HB}$ oxidation in exercising humans is modestly decreased by reduced $\mathrm{CHO}$ availability, independent of circulating $\beta \mathrm{HB}$ concentrations.

$\beta$-hydroxybutyrate oxidation, measured through the recovery of a ${ }^{13} \mathrm{C}$ label in respiratory gases, was impaired in the $\mathrm{KE}+\mathrm{FAT}$ (low $\mathrm{CHO}$, high fat availability) vs. $\mathrm{KE}+\mathrm{CHO}$ (high $\mathrm{CHO}$, normal fat availability) conditions. This was supported by an approximately 2 -fold increase in post-exercise intramuscular $\beta \mathrm{HB}$ in the $\mathrm{KE}+\mathrm{FAT}$ vs. $\mathrm{KE}+\mathrm{CHO}$ conditions. Given that endogenous $\beta \mathrm{HB}$ production is inhibited during exogenouslyinduced ketosis (27), we suggest this represents a "bottleneck" for ketone oxidation, rather than an increased supply of endogenous $\beta \mathrm{HB}$ from ketogenesis in the KE+FAT condition. The decrease in $\beta \mathrm{HB}$ oxidation occurred independently of circulating $\beta \mathrm{HB}$ levels, which were comparable between conditions pre-exercise (postdrink) and throughout exercise, meaning saturation kinetics were not responsible. Given that oxidation rates were low, only a small amount of $\beta \mathrm{HB}$ was "spared" in $\mathrm{KE}+\mathrm{FAT}$ condition. Over $60 \mathrm{~min}$ of exercise, the total additional $\beta \mathrm{HB}$ oxidized in the $\mathrm{KE}+\mathrm{CHO}$ vs. $\mathrm{KE}+\mathrm{FAT}$ conditions was just $\approx 1.9 \mathrm{~g}$ or $\approx 9 \mathrm{Kcal}$. For context, total energy expenditure during exercise was estimated to be 991 $\mathrm{Kcal}$ and $945 \mathrm{Kcal}$ in the $\mathrm{KE}+\mathrm{CHO}$ and $\mathrm{KE}+\mathrm{FAT}$ conditions, respectively. It is unlikely that this degree of ketone "sparing" would meaningfully affect skeletal muscle metabolism. As such, this finding has limited applicability toward the use of exogenous ketones to enhance human physical capacity (9).

To unpick whether low $\mathrm{CHO}$ or high fat availability modulated the observed decrease in $\beta \mathrm{HB}$ oxidation rates in the $\mathrm{KE}+\mathrm{FAT}$ vs. $\mathrm{KE}+\mathrm{CHO}$ conditions, we included a third experimental condition: $\mathrm{KE}+\mathrm{CHO}+\mathrm{FAT}$ (ketosis with high $\mathrm{CHO}$ and fat availability). We found that $\beta \mathrm{HB}$ oxidation was comparable between $\mathrm{KE}+\mathrm{CHO}$ and $\mathrm{KE}+\mathrm{CHO}+\mathrm{FAT}$ conditions, suggesting that circulating fat concentrations do not influence $\beta \mathrm{HB}$ oxidation rates and by extension, implicating $\mathrm{CHO}$ availability as an important mechanism. In support of this, we observed a moderate positive relationship between preexercise IMGLY and mean $\beta \mathrm{HB}$ oxidation rates during exercise. Glycogen is a major source of anaplerotic substrate for the Krebs cycle (15). Glucose 6-phosphate (G6P), via pyruvate and pyruvate carboxylase, may form oxaloacetate. Oxaloacetate is required for the entry of acetyl-CoA-derived from glycolysis, $\beta$-oxidation, and ketolysis, into the Krebs cycle. It is plausible, therefore, that a reduction in muscle glycogen content may impair muscle ketone oxidation rates due to a decrease in oxaloacetate and subsequent slowing of Krebs cycle flux.
However, no differences in measured Krebs cycle intermediates (citrate/isocitrate, malate, succinate, and $\alpha$-ketoglutyrate) were observed between conditions (unfortunately, we were unable to detect oxaloacetate abundance, which would have provided greater insight into the validity of this hypothesis). Furthermore, if a reduction in IMGLY availability was impairing Krebs cycle flux and ketone oxidation, by the same mechanism, fat oxidation would presumably have been decreased (both substrates being reliant on oxidative respiration). Yet, fat oxidation was markedly increased in the KE+FAT condition, as indicated by a lower RER and a significant decrease in post-exercise intramuscular acylcarnitines. Finally, if ketone metabolism were closely associated with IMGLY availability, we might expect $\beta \mathrm{HB}$ oxidation rates to progressively decline during $1 \mathrm{~h}$ exercise at $75 \% \mathrm{~W}_{\text {Max }}$; an intensity at which muscle glycogen is a major contributor to energy expenditure (28). However, $\beta \mathrm{HB}$ oxidation rates were stable throughout the exercise $(t=25,45$, and $60 \mathrm{~min})$. In sum, whilst we have demonstrated that $\beta \mathrm{HB}$ oxidation is modestly impaired by low $\mathrm{CHO}$ availability, we cannot attribute this to decreased IMGLY content perse.

Indeed, two observations prevent us from concluding that $\beta \mathrm{HB}$ oxidation rates were independent of elevated fat. First, $\beta \mathrm{HB}$ oxidation rates only tended to be different between $\mathrm{KE}+\mathrm{CHO}+\mathrm{FAT}$ and $\mathrm{KE}+\mathrm{FAT}$ conditions (both high fat conditions with either high $\mathrm{CHO}$ or low $\mathrm{CHO}$ availability, respectively). Notably, though, post-exercise intramuscular $\beta \mathrm{HB}$ was approximately 2 -fold greater in the $\mathrm{KE}+\mathrm{FAT}$ vs. $\mathrm{KE}+\mathrm{CHO}+\mathrm{FAT}$ condition, suggesting increased $\beta \mathrm{HB}$ clearance during exercise following a high- vs. low-CHO diet. We cannot discount, therefore, that the statistical similarity in $\beta \mathrm{HB}$ oxidation rates between $\mathrm{KE}+\mathrm{CHO}+\mathrm{FAT}$ and $\mathrm{KE}+\mathrm{FAT}$ conditions represents a type II error, particularly given the relatively small sample size studied. This is supported by exploratory post-hoc analyses (Supplementary Information 3), which indicated that $\beta \mathrm{HB}$ oxidation was greater in the $\mathrm{KE}+\mathrm{CHO}+\mathrm{FAT}$ vs. $\mathrm{KE}+\mathrm{FAT}$ condition at all time points during exercise with similar effect sizes to the $\mathrm{KE}+\mathrm{CHO}$ vs. $\mathrm{KE}+\mathrm{FAT}$ comparisons. Second, blood FFAs and intramuscular fat (determined by acylcarnitine abundance) were significantly greater in the $\mathrm{KE}+\mathrm{FAT}$ vs. $\mathrm{KE}+\mathrm{CHO}+\mathrm{FAT}$ condition. It is plausible that had circulating and intramuscular fat been similarly elevated in the $\mathrm{KE}+\mathrm{CHO}+\mathrm{FAT}$ condition, we would have observed a similar attenuation of $\beta \mathrm{HB}$ oxidation rates.

The overall contribution of $\beta \mathrm{HB}$ to oxygen consumption was $\approx 8.0 \%, \approx 8.4 \%$, and $\approx 7.4 \%$ in the $\mathrm{KE}+\mathrm{CHO}, \mathrm{KE}+\mathrm{GLAY}+\mathrm{FAT}$ (IMGLY replete conditions), and KE+FAT conditions, respectively. This is consistent with previous estimations of between 0 and $10 \%(4,6,10,11)$. Notably, using the same labeled $\mathrm{KE}$, we reported a maximum contribution of $\beta \mathrm{HB}$ to the oxygen consumption of $\approx 4.5 \%$ (6). Interindividual differences in ketone oxidation rates appear to be high (6), although the factors underlying this have not been fully elucidated. An important modulating factor of $\beta \mathrm{HB}$ oxidation rates may be an individual's training status (that is, trained vs. sedentary) (29). However, both studies recruited similarly well-trained athletes. Drink ${ }^{13} \mathrm{C}$ enrichment was 
approximately doubled in the present study. Yet given that $\beta \mathrm{HB}$ oxidation rates were calculated using TTR from study drinks and respiratory gas samples (see Methods for the calculations), this should not affect estimates (that is, greater drink enrichment should be matched by greater incorporation of the ${ }^{13} \mathrm{C}$ label in respiratory gas samples). Samples from this study were measured by gas chromatography-mass spectrometry separately from our previous work and thus we cannot discount measurement/instrument error as a factor. However, all respiratory gas and drink samples from the present study were analyzed as a single batch, meaning any measurement/instrument error is unlikely to effect relative changes in oxidation rates reported here.

Notwithstanding the higher oxidation rates reported here vs. our previous work (6) relative to those reported for $\mathrm{CHO}$ and fat (28), the contribution of $\beta \mathrm{HB}$ oxidation to overall energy expenditure was low in all conditions. Thus, the present work provides further support to the prevailing hypothesis that any ergogenic effect of exogenous ketones is derived from their metabolic signaling actions, rather than by providing an additional energetic substrate for exercising muscle (9).

\section{LIMITATIONS AND FUTURE DIRECTIONS}

Pre-exercise muscle glycogen levels were 3- to 5-fold lower than expected (30). Indeed, in all conditions (both high and low $\mathrm{CHO}$ availability), IMGLY content would be considered low $\left(<200 \mathrm{mmol} \cdot \mathrm{kg} \cdot \mathrm{dw}^{-1}\right)$ (30). Yet, participants reported consuming $\approx 11 \mathrm{~g} \mathrm{CHO} \cdot \mathrm{kg} \mathrm{bw}^{-1}$, which is in line with the gold-standard recommendations for glycogen restoration during exercise training (20). Thus, it appears likely that muscle glycogen levels were underestimated across all conditions. However, the accuracy of observed $\approx 70$ to $\approx 80 \mathrm{mmol}$ glycosyl units.kg dry $\mathrm{wt}^{-1}$ differences between high- and low-CHO availability conditions (for which this study was primarily concerned) are supported by the following: (i) selfreported pre-visit dietary $\mathrm{CHO}$ content being just $\approx 3 \%$ in the $\mathrm{KE}+\mathrm{FAT}$ condition $\approx 1 \mathrm{~g} \mathrm{CHO} \cdot \mathrm{kg} \mathrm{bw}^{-1}$; (ii) markedly elevated baseline blood FFA and intramuscular acylcarnitine abundance in the KE+FAT condition; (iii) decreased RER in the $\mathrm{KE}+\mathrm{FAT}$ vs. high $\mathrm{CHO}$ availability conditions during exercise at $t=10$ and $45 \mathrm{~min}$, and; (iv) increased perceived effort during exercise in the KE+FAT condition [low muscle glycogen content being associated with increased exercise fatigue (30)].

Work by Petrick et al. (14) demonstrated that ketones may support mitochondrial respiration, but their contribution is blunted by the addition of $\mathrm{CHO}$ - and lipid-derived substrates. The present work was lacking a glycogen depleted condition with low fat availability, which would have helped elucidate whether Petrick and colleagues', in vitro findings may be extrapolated to exercising humans and provided further insight into the mechanisms regulating ketone oxidation. However, the cost of the bespoke ${ }^{13} \mathrm{C} \beta \mathrm{HB}$ tracer meant that we were prohibited from recruiting a larger sample needed to power a fourth experimental condition. Indeed, the relatively small sample size also means the study is likely underpowered to detect changes in secondary outcome measures, most notably intramuscular metabolite measurements, which had high variation. As such, these measures are susceptible to type II error and should be considered exploratory.

\section{CONCLUSION}

$\beta \mathrm{HB}$ oxidation rates were modestly impaired by low $\mathrm{CHO}$ availability, independent of blood $\beta \mathrm{HB}$ concentration.

\section{DATA AVAILABILITY STATEMENT}

The original contributions presented in the study are included in the article/Supplementary Material, further inquiries can be directed to the corresponding author/s.

\section{ETHICS STATEMENT}

The studies involving human participants were reviewed and approved by East of England - Cambridgeshire and Hertfordshire Research Ethics Committee (14/EE/0063). The patients/participants provided their written informed consent to participate in this study.

\section{AUTHOR CONTRIBUTIONS}

PC and KC: study design. PC, DH, TK, DD, EK, AB, RE, and JR: conducting studies. PC, DD, DH, LH, TK, EC, EK, BS, AB, and JG: analysis. DD, PC, DH, and RE: manuscript preparation. All: manuscript editing.

\section{ACKNOWLEDGMENTS}

The authors thank the UK Ministry of Defence (Defence Science and Technology Laboratory) and UK Sport for funding this work. We also thank The Royal Commission for the Exhibition of 1851, who provided DD and BS with an Industrial Fellowship to sponsor their doctoral studies.

\section{SUPPLEMENTARY MATERIAL}

The Supplementary Material for this article can be found online at: https://www.frontiersin.org/articles/10.3389/fmed. 2021.721673/full\#supplementary-material 


\section{REFERENCES}

1. Cahill GF. Starvation in man. N Engl J Med. (1970) 320:668-75. doi: 10.1056/NEJM197003192821209

2. Owen OE, Morgan AP, Kemp HG, Sullivan, Herrera MG, Cahill GF. Brain metabolism during fasting. J Clin Investig. (1967) 46:1589-95. doi: 10.1172/JCI105650

3. Robinson AM, Williamson DH. Physiological roles of ketone bodies as substrates and signals in mammalian tissues. Physiol Rev. (1980) 60:143-87. doi: 10.1152/physrev.1980.60.1.143

4. Balasse E, Fery F. Ketone body production and disposal: effects of fasting, diabetes, and exercise. Diabetes Metab Rev. (1989) 5:247-70. doi: $10.1002 / \mathrm{dmr} .5610050304$

5. Balasse EO, Fery F, Neef M. Changes induced by exercise in rates of turnover and oxidation of ketone bodies in fasting man. J Appl Physiol Respir Environ Exerc Physiol. (1978) 44:5-11. doi: 10.1152/jappl.1978.44.1.5

6. Dearlove DJ, Harrison OK, Hodson L, et al. The effect of blood ketone concentration and exercise intensity on exogenous ketone oxidation rates in athletes. Med Sci Sports Exerc. (2021) 53:505-16. doi: 10.1249/MSS.0000000000002502

7. Kemp GJ, Thompson CH, Barnes PR, et al. Comparisons of ATP turnover in human muscle during ischemic and aerobic exercise using $31 \mathrm{P}$ magnetic resonance spectroscopy. Magn Reson Med. (1994) 31:248-58. doi: $10.1002 / \mathrm{mrm} .1910310303$

8. Margolis LM, O'Fallon KS. Utility of ketone supplementation to enhance physical performance: a systematic review. Adv Nutr. (2020) 11:412-9. doi: 10.1093/advances/nmz104

9. Evans M, Cogan KE, Egan B. Metabolism of ketone bodies during exercise and training: physiological basis for exogenous supplementation. J Physiol. (2017) 595:2857-71. doi: 10.1113/JP273185

10. Wahren J, Hagenfeldt L, Felig P. Splanchnic and leg exchange of glucose, amino acids, and free fatty acids during exercise in diabetes mellitus. J Clin Investig. (1975) 55:1303-14. doi: 10.1172/JCI108050

11. Wahren J, Sato Y, Ostman J. Turnover and splanchnic metabolism of free fatty acids and ketones in insulin-dependent diabetics at rest and in response to exercise. J Clin Investig. (1984) 73:1362-76. doi: 10.1172/JCI111340

12. Randle PJ, Garland PB, Hales CN, et al. The glucose fatty-acid cycle. Its role in insulin sensitivity and the metabolic disturbances of diabetes mellitus. Lancet. (1963) 1:785-9. doi: 10.1016/S0140-6736(63)91500-9

13. Hue L, Taegtmeyer $H$. The Randle cycle revisited: a new head for an old hat. Am J Physiol Endocrinol Metab. (2009) 297:E578-91. doi: 10.1152/ajpendo.00093.2009

14. Petrick HL, Brunetta HS, Pignanelli C, et al. In vitro ketone-supported mitochondrial respiration is minimal when other substrates are readily available in cardiac and skeletal muscle. J Physiol. (2020) 598:4869-85. doi: $10.1113 /$ JP280032

15. Taegtmeyer $\mathrm{H}$. On the inability of ketone bodies to serve as the only energy providing substrate for rat heart at physiological work load. Basic Res Cardiol. (1983) 78:435-50. doi: 10.1007/BF02070167

16. Murray B, Rosenbloom C. Fundamentals of glycogen metabolism for coaches and athletes. Nutr Rev. (2018) 76:243-59. doi: 10.1093/nutrit/nuy001

17. Winwood-Smith HS, Franklin CE, White CR. Low-carbohydrate diet induces metabolic depression: a possible mechanism to conserve glycogen. Am J Physiol Regul Integr Comp Physiol. (2017) 313:R347-56. doi: 10.1152/ajpregu.00067.2017

18. Currell K, Jeukendrup AE. Superior endurance performance with ingestion of multiple transportable carbohydrates. Med Sci Sports Exerc. (2008) 40:275-81. doi: 10.1249/mss.0b013e31815adf19

19. Holdsworth DA, Cox PJ, Kirk T, et al. A ketone ester drink increases postexercise muscle glycogen synthesis in humans. Med Sci Sports Exerc. (2017) 49:1789-95. doi: 10.1249/MSS.0000000000001292
20. Thomas DT, Erdman KA, Burke LM. Position of the academy of nutrition and dietetics, dietitians of Canada, and the American College of sports medicine: nutrition and athletic performance. J Acad Nutr Diet. (2016) 116:501-28. doi: 10.1016/j.jand.2015.12.006

21. Burke LM. Ketogenic low-CHO, high-fat diet: the future of elite endurance sport? J Physiol. (2021) 599:819-43. doi: 10.1113/JP278928

22. Cox PJ, Kirk T, Ashmore T, et al. Nutritional ketosis alters fuel preference and thereby endurance performance in athletes. Cell Metab. (2016) 24:256-68. doi: 10.1016/j.cmet.2016.07.010

23. Beylot $M$, Beaufrère $B$, Normand $S$, et al. Determination of human ketone body kinetics using stable-isotope labelled tracers. Diabetologia. (1986) 29:906. doi: 10.1007/BF00456116

24. Chong MFF, Fielding BA, Frayn KN. Mechanisms for the acute effect of fructose on postprandial lipemia. Am J Clin Nutr. (2007) 85:1511-20. doi: $10.1093 / \mathrm{ajcn} / 85.6 .1511$

25. van Loon LJ, Saris WH, Krushoop M, et al. Maximizing postexercise muscle glycogen synthesis: Carbohydrate supplementation and the application of amino acid or protein hydrolysate mixtures. Am J Clin Nutr. (2000) 72:106-11. doi: 10.1093/ajcn/72.1.106

26. Faul F, Erdfelder E, Lang A-G, et al. G*Power 3: a flexible statistical power analysis program for the social, behavioral, and biomedical sciences. Behav Res Methods. (2007) 39:175-91. doi: 10.3758/BF03193146

27. Mikkelsen $\mathrm{KH}$, Seifert T, Secher NH, et al. Systemic, cerebral and skeletal muscle ketone body and energy metabolism during acute hyper-D-Vhydroxybutyratemia in post-absorptive healthy males. J Clin Endocrinol Metab. (2015) 100:636-43. doi: 10.1210/jc.2014-2608

28. van Loon LJ, Greenhaff PL, Constantin-Teodosiu D, et al. The effects of increasing exercise intensity on muscle fuel utilisation in humans. J Physiol. (2001) 536:295-304. doi: 10.1111/j.1469-7793.2001.00295.x

29. Johnson RH, Walton JL. The effect of exercise upon acetoacetate metabolism in athletes and non-athletes. Q J Exp Physiol Cognate Med Sci. (1972) 57:73-9. doi: 10.1113/expphysiol.1972.sp002139

30. Hearris MA, Hammond KM, Fell JM, et al. Regulation of muscle glycogen metabolism during exercise: implications for endurance performance and training adaptations. Nutrients. (2018) 10:298. doi: 10.3390/nu10030298

Conflict of Interest: $\mathrm{KC}$ is the director of $\mathrm{T} \Delta \mathrm{S}$ Ltd., a spin-out company of the University of Oxford, established to develop and commercialise products based on the BHB monoester used in this study. DD is a current employee of T $\Delta \mathrm{S}$ Ltd and $\mathrm{TK}$ and $\mathrm{BS}$ are former employees. $\mathrm{AB}$ was employed by the company Sterling Pharma Solutions Ltd.

The remaining authors declare that the research was conducted in the absence of any commercial or financial relationships that could be construed as a potential conflict of interest.

Publisher's Note: All claims expressed in this article are solely those of the authors and do not necessarily represent those of their affiliated organizations, or those of the publisher, the editors and the reviewers. Any product that may be evaluated in this article, or claim that may be made by its manufacturer, is not guaranteed or endorsed by the publisher.

Copyright (c) 2021 Dearlove, Holdsworth, Kirk, Hodson, Charidemou, Kvalheim, Stubbs, Beevers, Griffin, Evans, Robertson, Clarke and Cox. This is an open-access article distributed under the terms of the Creative Commons Attribution License (CC $B Y)$. The use, distribution or reproduction in other forums is permitted, provided the original author(s) and the copyright owner(s) are credited and that the original publication in this journal is cited, in accordance with accepted academic practice. No use, distribution or reproduction is permitted which does not comply with these terms. 